\title{
Comunicação da ciência: perspectivas e desafios
}

Anabela Carvalho* e Rosa Cabecinhas**

O presente número da revista Comunicação e Sociedade é dedicado à temática da comunicação da ciência. Importa começar por reflectir sobre o perfil desta área de estudos e sobre a sua inserção no campo das ciências da comunicação e noutras disciplinas.

'Comunicação da ciência' é uma expressão com múltiplos sentidos. Frequentemente associada à divulgação pública do conhecimento científico, a comunicação da ciência tem várias outras facetas, da comunicação entre cientistas à ficção científica no cinema. O próprio conceito de ciência, na expressão 'comunicação da ciência', pode ser problematizado: falamos de investigação científica, apenas, ou também das aplicações da pesquisa, alargando então o conceito à tecnologia?

Uma das formas de mapeamento deste campo é a identificação de arenas e actores relevantes. Assim, poderemos apontar como principais - mas não exclusivos - os seguintes: governo e organismos estatais, comunidade científica, escolas e todo o sistema educativo, museus de ciência, meios de comunicação social e indústria. A estas arenas e actores liga-se uma grande variedade de papéis sociais, de lógicas e modos de funcionamento, de discursos e de tecnologias de comunicação.

Não é, portanto, de estranhar que o carácter já de si plural das ciências da comunicação se amplie no estudo da comunicação da ciência. A sociologia, a psicologia, a filosofia e a linguística são apenas alguns exemplos da grande variedade de disciplinas que se tem interessado pelas questões de comunicação e linguagem na ciência, o que naturalmente implica uma multiplicidade de quadros teóricos e opções metodológicas de pesquisa.

Nos processos de interacção social envolvidos na construção do conhecimento científico, na sua 'validação' pela comunidade científica e na sua afirmação social podem desde logo apontar-se questões comunicacionais muito importantes (e. g., Gross, 1990). A um nível mais fundamental, o pensamento e as operações mentais presentes no trabalho científico não são possíveis sem linguagem e sem comunicação.

\footnotetext{
* Departamento de Ciências da Comunicação, Instituto de Ciências Sociais, Universidade do Minho. E-mail: carvalho@ics.uminho.pt

** Departamento de Ciências da Comunicação, Instituto de Ciências Sociais, Universidade do Minho.
} 
Para o cidadão comum, uma das principais formas de contacto com os mundos da ciência é a educação escolar. Para a relação que os indivíduos manterão ao longo da vida com a ciência, são cruciais a aprendizagem e o interesse desencadeados pelo sistema de ensino. Embora de natureza multidisciplinar, a pesquisa sobre educação para a ciência tem sido desenvolvida em campos distintos do das ciências da comunicação.

Já na vida adulta, o acesso à ciência ocorre, para a maior parte dos indivíduos, através dos media. No dia-a-dia do cidadão comum, jornais, revistas e televisão são fundamentais para a tomada de conhecimento e formação de opinião sobre os desenvolvimentos na investigação e as implicações da mesma. A mediatização da ciência, como de outras esferas da vida social, é influenciada por um conjunto de normas jornalísticas e critérios de selecção e construção noticiosa (e. g., Nelkin, 1987). O interesse do público, por exemplo, é um princípio fundamental na cultura profissional do jornalismo que não é estruturante para o modo de pensar e comunicar dos cientistas. Por outro lado, todo o jornalismo depende de um conjunto de pressões e limitações editoriais que se repercutem na re-construção discursiva da ciência nos media.

Mas a comunicação da ciência nos media passa por muitos outros géneros e formatos, para além do da notícia. Os documentários sobre natureza, os debates, os programas infantis e juvenis, por exemplo, são tão ou mais influentes na construção de representações mentais da ciência. O papel da ficção na comunicação da ciência na literatura, no cinema, na televisão - só recentemente tem sido objecto de análise mais sistemática ${ }^{1}$ e deverá merecer uma atenção continuada.

Naturalmente, há formas de interacção dos públicos com a ciência que se podem conceber como menos 'mediadas', tais como os museus de ciência e as exposições científicas. Aí o contacto é, por certo, mais imediato com a materialidade da ciência - os seus aparatos técnicos, as suas 'matérias-primas' - mas igualmente indirecto no que diz respeito às ideias, aos agentes produtivos, aos contextos sociais. As técnicas e tecnologias da comunicação têm, portanto, também aí, uma função vital.

Nesta linha, há que destacar o papel que a Internet vem assumindo na medida em que potencia novos modos de (co-)construção e disseminação da ciência. Assim, um desafio importante para a investigação será o aprofundamento do estudo da comunicação e das formas de consumo de informação sobre ciência na Internet e em canais multimédia.

A pesquisa sobre comunicação da ciência tem tido uma importante expressão nos estudos sobre 'compreensão pública da ciência' (e. g., Gonçalves, 2002; Costa, Ávila \& Mateus, 2002). Apesar da centralidade da investigação sobre a relação do públi$\mathrm{co}^{2}$ com a ciência não é unânime, sequer, a natureza do objecto de análise. O que se considera importante estudar varia entre a percepção, a representação social, o conhecimento, o interesse, a aprovação e outras dimensões dessa relação. Mesmo o

\footnotetext{
${ }^{1}$ Ver a edição de Julho de 2003 da revista Public Understanding of Science, vol.12 (3).

${ }^{2}$ Apesar do uso generalizado do conceito de 'público' será, muitas vezes, mais adequado falar de públicos, dado que nos estamos a referir a uma grande diversidade de grupos ou sectores da sociedade, quer em termos da sua caracterização sociodemográfica, quer em termos da sua relação com a informação sobre ciência.
} 
entendimento do termo 'literacia científica' não tem sido consensual (Miller \& Pardo, 2000): para alguns refere-se aos níveis de conhecimento científico, para outros à familiaridade com os métodos da ciência e para outros ainda ao conhecimento sobre os modos de funcionamento da ciência. Pensamos que todas estas dimensões do saber - factual, metodológico e sociológico - são essenciais e deverão ser estudadas de forma integrada.

O debate académico tem tido um equivalente político que se manifestou durante muito tempo na preocupação de vários organismos estatais em conhecer e promover os níveis de interesse do público pela ciência e actualmente toma corpo em discursos sobre governação participativa da ciência, à mistura com a velha retórica educativa, mais ou menos explícita. A este nível, há também matéria para análise e reflexão.

Quer o estudo quer as políticas da comunicação da ciência têm tido uma significativa influência normativa na medida em que se tem defendido a necessidade de mais e melhor comunicação, querendo dizer, na maior parte dos casos, divulgação. O pressuposto básico é, muitas vezes, o de que a ciência é um bem em si. Para além disso, tem-se associado a ciência a vantagens económicas e políticas: o conhecimento científico da população seria um garante de vitalidade económica, conduzindo, por exemplo, a melhores decisões de consumo, e um pilar importante de uma sociedade democrática.

Apesar de profundamente contestado em termos de quadros teóricos, de metodologias e de princípios ideológicos, o estudo da compreensão da ciência pelo público conheceu uma evolução muito significativa nas últimas duas décadas. O 'modelo do défice cognitivo' foi, em larga medida, substituído pelo 'modelo interactivo'. No primeiro, o público é visto como um recipiente de informação científica e a principal finalidade é (compreender como) elevar o seu nível de conhecimento (Royal Society, 1985). No segundo modelo, considera-se que a relação do público com a ciência tem que ser analisada em contextos socioculturais específicos e envereda-se por uma abordagem construtivista em que o saber resulta da interacção da informação e da experiência (Irwin \& Wynne, 1996). Assim, as preocupações com a eficácia da transmissão de conhecimento deram lugar a um quadro de análise mais complexo. No estudo da 'construção' do conhecimento pelos públicos e dos processos comunicacionais em torno da ciência, a agenda de investigação deverá passar, julgamos, pelo cruzamento de conceitos e metodologias das várias disciplinas atrás enunciadas.

$\mathrm{Na}$ cultura profissional dos cientistas, a comunicação da ciência foi longamente percebida como 'popularização' e vista como actividade prosélita reservada a um pequeno grupo de investigadores, como Carl Sagan e Stephen Hawkings. A maior parte dos cientistas tem, de facto, hesitado em construir pontes com públicos não especializados. O contacto com os media, em particular, tem sido frequentemente temido devido aos riscos de simplificação excessiva, de deturpação de resultados e de sensacionalismo (e. g., Friedman, Dunwoody \& Rogers, 1986). Receando os males da exposição pública e a desaprovação dos seus pares, os cientistas muitas vezes confinam-se aos seus círculos e circuitos fechados. No entanto, tem havido algumas 
mudanças significativas na actuação dos cientistas em espaços públicos, por um lado, motivadas pela percepção do carácter estratégico da mediatização como forma de promoção social (Bucchi, 1998), mesmo dentro das comunidades científicas, por outro lado, accionadas pela consciencialização da responsabilidade social da profissão (desde logo, o recurso a financiamento público criaria uma obrigação ética de 'prestar contas' aos cidadãos). Assim, vêm-se afirmando atitudes mais pró-activas no contacto com os públicos, através dos media e em outras arenas.

$\mathrm{O}$ aumento da participação de agentes económicos privados nalguns campos de investigação, como a biotecnologia e a farmacêutica, está também a motivar transformações ao nível da comunicação com os públicos. Associada a esta alteração, a profissionalização da comunicação da ciência, com a entrada de especialistas em assessoria de imprensa e relações públicas no campo, traz novos dados que importa compreender melhor. Esta é, como tal, outra avenida importante da pesquisa a levar a cabo.

Nos programas de investigação sobre comunicação da ciência, há também que colocar as ciências sociais e humanas. Tradicionalmente minoritárias, senão excluídas das agendas mediáticas, estas áreas têm também sido muito secundarizadas nos estudos académicos sobre comunicação da ciência (uma excepção é Fenton et al., 1998). A actuação dos vários actores sociais, dos organismos de Estado aos cientistas, no que concerne as ciências sociais e humanas, e a percepção das mesmas por parte dos públicos são terreno fértil a explorar.

A diversidade de ângulos de análise da comunicação da ciência tem uma clara expressão nesta edição, como sumarizado abaixo. A multidisciplinaridade da investigação sobre esta temática está também aqui bem patente, já que os autores dos artigos têm uma grande variedade de afiliações, quer nos campos das ciências 'exactas', quer no das ciências sociais e humanas.

A relação entre os saberes 'científicos' e os saberes 'leigos' é o objecto de análise de Carmen Diego Gonçalves. O lugar da ciência e do conhecimento científico na cultura nas chamadas 'sociedades de risco' é discutido, no seu texto, a partir da análise dos discursos de cientistas portugueses, recolhidos através de entrevistas semi-estruturadas efectuadas pela autora.

Anabela Carvalho reflecte sobre alterações recentes nas estratégias de comunicação pública dos cientistas, no envolvimento dos públicos nos processos de decisão e na (re)construção social da ciência pelos jornalistas. Uma comunicação mais 'crítica' da ciência parece estar a desenvolver-se, com novas responsabilidades para uma variedade de actores sociais e implicações importantes para a cidadania. Neste contexto, o artigo sugere que o papel dos media deverá (continuar a) ser objecto de especial atenção.

Debruçando-se sobre a mediatização da biotecnologia, Anders Hansen analisa os usos discursivos do conceito de 'natureza' e, em especial, a forma como é invocado para legitimar determinados pontos de vista nos debates públicos sobre este campo. $\mathrm{O}$ autor discute amplamente a literatura sobre representações da natureza e apresenta 
os resultados de um estudo empírico da cobertura da investigação genética em cinco jornais britânicos.

Sharon Dunwoody aborda a questão da formação de base dos jornalistas de ciência. Será que a educação formal no campo das ciências é fundamental para um bom desempenho profissional? Analisando a investigação desenvolvida sobre esta comunidade profissional, a autora responde negativamente à questão e propõe pistas de investigação sobre o tema.

Dois artigos apresentam experiências inovadoras de comunicação da ciência realizadas recentemente no nosso país. Mónica Bettencourt-Dias, Ana Godinho Coutinho e Sofia Jorge Araújo organizaram um workshop em que participaram diversos investigadores portugueses de diferentes áreas científicas com o objectivo de melhorar as suas competências ao nível da comunicação. Na avaliação que efectuaram desta actividade, as autoras concluem que os investigadores ganharam confiança nas suas capacidades de comunicar e de participar em actividades que envolvam comunicação pública da ciência.

No texto seguinte, Ana Godinho Coutinho, Sofia Jorge Araújo e Mónica Bettencourt-Dias discutem diferentes perspectivas sobre o estabelecimento de formas de diálogo entre cientistas e o público. As autoras organizaram e avaliaram uma conferência pioneira em Portugal entre cientistas do Instituto Gulbenkian de Ciência e o público de Oeiras, onde o instituto se localiza, tendo concluído que o diálogo entre cientistas e o público é possível, viável e promove maior envolvimento do público com a ciência.

O artigo de António Fernando Cascais centra-se na dimensão retórica da ciência, particularmente no que diz respeito às funções dos 'resultados' científicos nos discursos. Obscurecendo o processo produtivo e todas as suas contingências, falhas e imprevisibilidades, a 'retórica dos resultados' consolida, como argumenta o autor, a ideia de controlo na leitura social da tecnociência.

Juliana Mezzomo e Clélia Maria Nascimento-Schulze apresentam um estudo empírico realizado com alunos do ensino médio no Brasil no qual se avalia o impacto de uma exposição científica nas representações sociais sobre 'meio ambiente' e no desenvolvimento informativo e cognitivo dos alunos.

A Internet tem vindo a alterar de forma substancial os processos de partilha e divulgação da ciência, quer no seio das comunidades científicas quer desta com as comunidades envolventes. Dois artigos centram-se especificamente nesta problemática. Lídia Silva discute os resultados obtidos num estudo empírico realizado junto da comunidade científica portuguesa sobre as potencialidades da Internet na disseminação da investigação, na promoção das instituições de pesquisa, no fomento de colaboração entre investigadores e noutros aspectos da actividade científica.

Por seu turno, Sueli Ferreira, Fernando Modesto e Simone da Rocha Weitzel discutem a importância dos repositórios electrónicos na divulgação do conhecimento científico. Por um lado, os autores definem os pressupostos teóricos subjacentes ao modelo de comunicação científica, apresentando os repositórios institucionais como um processo de comunicação menos centralizado e mais distribuído; por outro, analisam a 
implementação de uma iniciativa no Brasil para a criação de um repositório na área específica das Ciências da Comunicação, com interesses alargados ao espaço lusófono.

Dois outros artigos debruçam-se sobre a problemática da invenção e da criatividade a partir de estudos de caso de inventores independentes em Portugal. Actualmente, os inventores independentes constituem uma franja minoritária da produção técnico-científica, assistindo-se a uma progressiva institucionalização do processo inventivo. Assim, Carolina Leite e Silvana Mota-Ribeiro, partindo de uma perspectiva geo-sociológica da invenção, destacam os factores favoráveis à emergência desta. As autoras discutem ainda os factores potenciadores do gosto pela invenção, partindo dos discursos dos próprios inventores independentes.

No âmbito do mesmo projecto, Fátima Morais procede à análise dos testemunhos de inventores independentes portugueses, tendo como grelha de leitura modelos da psicologia cognitiva sobre a pessoa e o processo criativos. Intercalando os modelos teóricos com frases ilustrativas dos entrevistados, a autora vai discutindo as características de personalidade geralmente atribuídas à pessoa criativa e ilustrando as diferentes fases do processo criativo.

$\mathrm{Na}$ parte final desta edição, um geólogo (José Brilha) e um biólogo (Rui Oliveira) reflectem sobre os problemas na comunicação com o público no âmbito das suas disciplinas. Enquanto José Brilha identifica um conjunto de factores sociais e políticos que reduzem a visibilidade pública da Geologia, Rui Oliveira centra-se na mediatização da pesquisa sobre organismos geneticamente modificados.

\section{Referências}

Bucchi, M. (1998) Science and the Media: Alternative Routes in Scientific Communication, London: Routledge.

Costa, A. F., Ávila, P. \& Mateus, S. (2002) Públicos da Ciência em Portugal, Lisboa: Gradiva.

Fenton, N., Bryman, A., Deacon, D. with Birmingham, P. (1998) Mediating Social Science, London: Sage.

Friedman, S., Dunwoody, S. \& Rogers, C. (eds.) (1986) Scientists and Journalists: Reporting Science as News, New York: Free Press.

Gonçalves, M. E. (org.) (2002) Os Portugueses e a Ciência, Lisboa: Dom Quixote.

Gross, A. (1990) The Rhetoric of Science, Cambridge, MA: Harvard University Press.

Irwin, A. \& Wynne, B. (1996) Misunderstanding Science? The Public Reconstruction of Science and Technology, Cambridge: Cambridge University Press.

Miller, J. D. \& Pardo, R. (2000) 'Civic Scientific Literacy and Attitude to Science and Technology' in Dierkes, M. \& Von Grote, C. (eds.) Between Understanding and Trust: The Public, Science and Technology, Amsterdam: Harwood, pp.81-129.

Jasanoff, S. (1990) The Fifth Branch: Science Advisers as Policymakers, Cambridge, MA and London: Harvard University Press.

Nelkin, D. (1987) Selling Science. How the Press Covers Science and Technology, New York: W. H. Freeman. Royal Society (1985) The Public Understanding of Science, London: Royal Society. 